Mini Review

\title{
Application of biosensors in the petrochemical industry: a mini review on the sensing platforms for polycyclic aromatic hydrocarbons detection
}

\begin{abstract}
The increased awareness of the hazardous effects of polycyclic aromatic hydrocarbons (PAHs) has been the target of several studies in the current literature. $\mathrm{PAHs}$ are a group of organic molecules derived from petroleum that contains from two to seven aromatic rings in their structure that have been largely emitted to the environment from natural but especially anthropogenic sources. In this research, we reviewed the main aspects concerning the effects of PAHs in the environment with a special focus on the biosensing platforms recently developed to detect these pollutants. Herein, we reported the use of biosensors as an alternative to the expensive, time-consuming and laborious traditional techniques commonly employed to detect PAHs. Most of the examined literature referred to the use of antibodies and DNA as biological elements to fabricate the sensors, and the electrochemical and optical mechanisms comprised the preferred transduction techniques for this purpose. Among the 16 PAHs present in the priority list established by the United States Environmental Protection Agency (US EPA) with respect to the toxicity and abundance, $\mathrm{B}[a] \mathrm{P}$ was the pollutant most studied by researchers in the field of biosensors, who found limits of detection in the order of micro molar. Overall, the reviewed biosensors presented significant promise for the reliable, selective and sensitive detection of PAHs in the ecosystem.
\end{abstract}

Keywords: polycyclic aromatic hydrocarbon, biosensor, petroleum, contamination
Volume 5 Issue 5 - 2019

\section{Vitor Azevedo Vasconcellos, Vanessa de Freitas Cunha Lins, Ricardo Adriano Dorledo de Faria}

Department of Chemical Engineering, Universidade Federal de Minas Gerais, Brazil

\section{Correspondence: Ricardo Adriano Dorledo de Faria,} Department of Chemical Engineering, Universidade Federal de Minas Gerais (UFMG), Belo Horizonte, Minas Gerais 30270-901, Brazil.Email ricardo.adriano08@hotmail.com

Received: September 22, 2019 | Published: October 01, 2019
Abbreviations: US EPA, united states environmental protection agency; PAHs, polycyclic aromatic hydrocarbons

\section{Introduction}

The exponential population growth and the consequent accelerated industrial development have contributed even more in the past decades to put petroleum as a major source of energy worldwide. Contrary to the contribution of the oil to the economic and social development, though, the occurrence of ecosystem contamination has been a serious concern mainly because it results into a potential risk to public health as well as to biodiversity of flora and fauna. ${ }^{1,2}$ Several activities related to petroleum exploiting (i.g. transport, refining, storing and use at sea and/or land) can lead to the contamination of water, air and soil in cases of unintentional or operational incidents. ${ }^{3}$ According to Zaki et al. ${ }^{4}$ approximately 35 million barrels of petroleum are transported annually in the world, posing the aquatic environment in risk due to the possibility of oil spill accidents. The authors reported that, from 1990 to 2001, more than two hundred accidents were registered involving the transport of oil by ships. Amongst important constituents of petroleum like alkanes and alkenes, polycyclic aromatic hydrocarbons (PAHs) have merited special global attention for posing great threat to humans' and environmental health as well as for the ubiquity of these contaminants sources. ${ }^{5}$

PAHs comprise a group of thousands of organic compounds containing 2-7 fused aromatic rings in different configurations, originated from both natural and anthropogenic activities and which occurs in the ecosystem as colorless, white or pale yellow solids. ${ }^{6,7}$ Usually, PAHs mainly arise from natural incomplete combustion processes in forests and brush fires or from combustion sources provoked by human action, entering the soil, water and air as a harm contaminant. Accordingly, due to the large abundance of these compounds in the environment, researches have devoted great attention towards the development of analytical methods for the detection of PAHs. ${ }^{8}$ The group of conventional assays for PAHs detection include liquid chromatography with fluorescence detection, gas chromatography, high-performance liquid chromatography and mass spectrometry. ${ }^{9}$ In this regard, Hahm et al. ${ }^{9}$ enlist two important negative aspects of the chromatography: the longtime required for sample preparation and the incompatibility of the hydrocarbons with the chromatographic column. Behera et al. ${ }^{10}$ confirm the difficulty in preparing the samples as a major issue in using aforementioned techniques for detecting PAHs, mainly because of the volatility and lipophilic nature of these compounds that can alter their integrity from the collection to the analysis. Moreover, the researchers cite the unitary cost of each assay and the high expertise required to perform the detection as other disadvantages of the conventional methods. For a simple, quick, cost-effective and in situ detection of PAHs in their various possibilities of environments, Behera et al. ${ }^{10}$ mention the biosensors as promising candidates to overcome the limitations of the current assays. Biosensors belong to a category of analytical devices that are capable to provide a measurable output signal by means of the recognition of a particular substance of interest by a biological unit of recognition (probe). The selective biochemical interaction between the probe and the analyte generates a signal that is converted by a transducer element in the device. The magnitude of the output signal is proportional to the analyte concentration and can be interpreted to infer about the biosensor's limit of detection (LOD), selectivity and linearity. ${ }^{11}$ In our previous publications, ${ }^{11-13}$ we have reported that the probe is one of the main components in 
the biosensor configuration because it can provide, especially, great selectivity to the device. Antibodies, antigens, enzymes, whole cells, organelles, microorganisms, tissues, etc. are the main examples of biological elements used in the development of biosensors aiming to achieve high levels of sensitivity and selectivity towards the analytes of interest. ${ }^{11}$ Accordingly and inspired by the promising features of biosensors, the purpose of this research was to review the current scientific contributions on the topic of biosensing platforms for detection and quantification of PAHs in the environment.

\section{Environmental impact and health effects of hydrocarbons}

Due to the moderate solubility and the facility to be absorbed by soil particles, Wang et al. ${ }^{14}$ point the soil as the major reservoir for PAHs in the ecosystem (it is estimated that $90 \%$ of total residues are found in the soil). However, several studies are also devoted to the presence of PAHs in aquatic environments due to the risk they represent to the marine fauna and flora. ${ }^{6,14-16}$ In this regard, Zhang et al. ${ }^{17}$ discussed the effect of PAHs in living organisms due to the contamination of soil and water, highlighting the leaf injuries in plants, the negative impact on photosynthesis and biomass production as well as their toxic effects on animals. The PAHs hazard to environment and to humans' health lies on their great abundance and high toxicity. Since the main source of PAHs are the anthropogenic activities, the highest levels of the pollutants in the air occur in big urban centers with high industrial activity and pose great risk to human life. Over the past twenty years, for instance, the concentration of $\mathrm{B}[\mathrm{a}] \mathrm{P}$ was approximately equal to $0.3 \mathrm{ng} \cdot \mathrm{m}^{-3}$ in Houston (USA), $0.6 \mathrm{ng} \cdot \mathrm{m}^{-3}$ in London (United Kingdom), 9.3 ng. $\mathrm{m}^{-3}$ in Lahore (Pakistan) and 11 ng. $\mathrm{m}^{-3}$ in Santiago (Chile). ${ }^{18}$ The United States Environmental Protection Agency (US EPA) classified 16 priority PAHs (Table 1) with respect to their potential risk to humans' health. Zelinkova \& Wenz $l^{19}$ pointed out that this list does not set up the compounds only by the toxicity but it also prioritizes their frequency of occurrence and potential for human exposure.

Table I Sixteen priority PAHs enlisted by US EPA

\begin{tabular}{|c|c|c|c|}
\hline PAH & Molecular formula & Molecular weight $\left(\mathrm{g} \cdot \mathrm{mol}^{-1}\right)$ & Chemical structure \\
\hline Naphtalene & $\mathrm{C}_{10} \mathrm{H}_{8}$ & 128.2 & \\
\hline Acenaphthylene & $\mathrm{C}_{12} \mathrm{H}_{8}$ & 152.2 & \\
\hline Acenaphthene & $\mathrm{C}_{12} \mathrm{H}_{10}$ & 154.2 & \\
\hline Fluorene & $\mathrm{C}_{13} \mathrm{H}_{10}$ & 166.2 & \\
\hline Anthracene & $\mathrm{C}_{14} \mathrm{H}_{10}$ & 178.2 & \\
\hline Phenanthrene & $\mathrm{C}_{14} \mathrm{H}_{10}$ & 178.2 & \\
\hline
\end{tabular}


Table Continued

\section{$\mathrm{PAH}$}

$\mathrm{C}_{16} \mathrm{H}_{10}$

$\mathrm{C}_{16} \mathrm{H}_{10}$

202.3

Pyrene

Chrysene

$\mathrm{C}_{18} \mathrm{H}_{12}$

Benz[a]anthracene

$\mathrm{C}_{18} \mathrm{H}_{12}$

228.3<smiles>c1ccc2c(c1)ccc1c3ccccc3ccc21</smiles><smiles>c1ccc2cc3c(ccc4ccccc43)cc2c1</smiles><smiles></smiles>

Benzo[b]fluoranthene,

$\mathrm{C}_{20} \mathrm{H}_{12}$

252.3<smiles>c1cc2ccc3cccc4ccc(c1)c2c34</smiles>

Chemical structure<smiles></smiles><smiles>c1ccc2cc3c(cc2c1)-c1cccc2cccc-3c12</smiles> 


\begin{tabular}{|c|c|c|c|}
\hline $\mathrm{PAH}$ & Molecular formula & Molecular weight $\left(\mathrm{g} \cdot \mathrm{mol}^{-1}\right)$ & Chemical structure \\
\hline $\mathrm{B}[a] \mathrm{P}$ & $\mathrm{C}_{20} \mathrm{H}_{12}$ & 252.3 & \\
\hline Indeno[I,2,3-cd]pyrene & $\mathrm{C}_{22} \mathrm{H}_{12}$ & 276.3 & \\
\hline Benzo[g,h,i]-perylene & $\mathrm{C}_{22} \mathrm{H}_{12}$ & 276.3 & \\
\hline Dibenz $[a, h]$ anthracene & $\mathrm{C}_{22} \mathrm{H}_{14}$ & 278.4 & \\
\hline
\end{tabular}

Carcinogenic effect of PAHs arises from their capability to bind to DNA. ${ }^{20}$ The exposure to the pollutants occurs via the ingestion of contaminated food and water, inhalation, contact with the skin and mucosal accesses and by smoking cigarettes. ${ }^{18,21}$ The severity of the exposure to PAHs depends on the exact length of exposure time, the concentration of the pollutant, the route of absorption in the body and pre-disposition to some diseases related to health conditions and age. In general, short and long-term exposures to PAHs can causes from softer symptoms like allergic responses, diarrhea, nausea and vomiting up to carcinogenic, teratogenic and mutagenic problems. ${ }^{18}$ US EPA adapted a methodology for estimating the toxicity equivalency fact (TEF) in order to inspect the health effects of PAHs. In this method, one compares the toxicity of a certain $\mathrm{PAH}$ to $\mathrm{B}[a]$ $\mathrm{P}$, which is a compound whose carcinogenic properties are widely studied as a reference. Thus, the toxicity potential of a studied PAH is the product between its concentration and the estimated TEF value. In air samples for instance, in which the PAHs are present as a mixture, the global toxicity is the sum of the individual contributions of each PAH compound. ${ }^{20}$ According to the International Agency for Research on Cancer (IARC), ${ }^{22}$ the PAHs can be categorized into probably carcinogen (2A) and possibly carcinogen (2B) with respect to their toxic potential. Bolden et al. ${ }^{21}$ reported that the exposure to PAH also implicates in reproductive disorders. By reviewing extensive literature on this domain, the authors related the influence of PAHs on the estrogen and androgen receptors as well as the influence of these pollutants on pregnancy/fetal viability. A neglected issue in the general impact of hydrocarbons is the food contamination. Purcaro et al. ${ }^{23}$ highlight that this kind of contamination represents an important risk to humans' health because it can occurs at any stage of the food production, because the regulation on this topic is still fragile and even due to the difficulty to predict the source of the contaminant. The authors cite that mineral oil hydrocarbons enter food products by air in case of volatile compounds, in aquatic environments, through industrial processing (due to the use of food grade mineral oils like some lubricants, protective food coatings and some additives) and harvesting by machines or even during the contact with packaging. Ledesma et al. ${ }^{24}$ studied the effect of the smoking process of meat products as a source of carcinogenic PAH. In their report, they explain 
that the mechanism of PAH formation in the smoking process arises from the biomass pyrolysis. During the combustion process, PAHs are formed as tertiary tar products above $750^{\circ} \mathrm{C}$, whose aerosol pass through the smoking chamber and goes towards the meat. In their study, Fasano et al. ${ }^{25}$ found that fluoranthene and pyrene, which are harmless low molecular weight compounds, represented the major fraction of PAHs contamination in some traditional Spanish food. The authors considered the presence of total PAHs at $3.4 \mu \mathrm{g} \cdot \mathrm{kg}^{-1}$ in Pan de Cea bread as negligible and that it does not represent a risk to the health. In meat sausage and cheese, the presence of PAHs was approximately $100 \%$ in the casing and rind respectively. The higher levels of carcinogenic PAH, though, was detected in Pimentón de la Vera paprika, but the authors assume that is not a severe risk to the health once paprika is a non-frequent condiment in people's diet and it is consumed in small amounts.

\section{Biosensors for PAHs detection}

Since the regulation on the PAHs domain mainly refers to the concentration of the compounds that poses risk to human's health and to the ecosystem, researchers on the topic of analytical methods have been greatly motivated to develop biosensing platforms for detecting and quantifying the PAHs. ${ }^{18}$ The classification of biosensors is based on the type of the transduction mechanism (i.g. optical, electrochemical and piezoelectric) or on the type of the biological element of recognition used as a probe (i.g. antibodies, enzymes and DNA). ${ }^{10}$ As a strategy to achieve highly sensitive and selective biosensors, researchers have worked on combining different transducer/probe pairs to detect PAHs in the environment. Table 2 summarizes the achievements of some literature on biosensors developed for the detection of important PAHs by means of various combinations of probes and transduction mechanisms..$^{26-31}$

Table 2 Biosensors reported in the recent literature for the detection of PAHs

\begin{tabular}{|c|c|c|c|c|c|}
\hline Analyte & Probe & Environment & $\begin{array}{l}\text { Transduction } \\
\text { technique }\end{array}$ & LOD [nM] & Reference \\
\hline Naphtalene & $\begin{array}{l}\text { Acinetobacter ADPWH_ } \\
\text { Nah bioreporter }\end{array}$ & Groundwater and soil & Bioluminescence & 0.10 & 26 \\
\hline $\mathrm{B}[a] \mathrm{P}$ & $\begin{array}{l}\text { Anti-B }[a] \mathrm{P} \text { monoclonal } \\
\text { antibody }\end{array}$ & River water & $\begin{array}{l}\text { Capacitance measu- } \\
\text { rement }\end{array}$ & $3.96 \times 10^{-3}$ & 27 \\
\hline $\mathrm{B}[a] \mathrm{P}$ & $\begin{array}{l}\text { DNA/hemin/nafion-gra- } \\
\text { phene }\end{array}$ & Water & $\begin{array}{l}\text { Differential Pulse } \\
\text { Voltammetry }\end{array}$ & 0.11 & 28 \\
\hline $\mathrm{B}[a] \mathrm{P}$ & $\begin{array}{l}\text { DNA/Anti-B }[a] P \text { mono- } \\
\text { clonal antibody }\end{array}$ & Cigarette & $\begin{array}{l}\text { Rapid fluorescence } \\
\text { immunoassay }\end{array}$ & 1.27 & 29 \\
\hline $\begin{array}{l}\text { Pyrene and homolo- } \\
\text { gous PAHs }\end{array}$ & $\begin{array}{l}\text { Biotinylated reporter } \\
\text { DNA }\end{array}$ & $\begin{array}{l}\text { Mineral, tap and river } \\
\text { waters }\end{array}$ & $\begin{array}{l}\text { Real-time Immuno- } \\
\text {-polymerase chain } \\
\text { reaction }\end{array}$ & $4.50 \times 10^{-4}$ & 30 \\
\hline Phenanthrene & $\begin{array}{l}\text { Anti-phenanthrene mo- } \\
\text { noclonal antibody }\end{array}$ & Tap and river waters & Amperometry & $1.40 \times 10^{-3}$ & 31 \\
\hline
\end{tabular}

Regarding the advantageous capability of biosensors in providing high levels of sensitivity and selectivity, Beloglazola et al. ${ }^{27}$ compared the use of a molecularly imprinted polymer and a monoclonal antibody as probes to detect $\mathrm{B}[a] \mathrm{P}$. In their findings, the biological probe was demonstrated to be more sensitive (about a thousand times). Furthermore, the authors also compared the performance of the anti- $\mathrm{B}[a] \mathrm{P}$ antibodies in their capacitive immunosensor and in an ELISA reference method. Their results revealed a similar selectivity towards the studied PAH and a higher sensitivity of the capacitive immunosensor $\left(1 \mathrm{ng} . \mathrm{L}^{-1}\right)$ in comparison to the ELISA technique (20 ng. $\left.\mathrm{L}^{-1}\right)$. Sun et al. ${ }^{26}$ selectively detected naphthalene within $1 \mathrm{~h}$ at various concentrations and verified very low or even null ratios between the optical signal derived from naphthalene recognition and those from toluene, anthracene, pyrene and phenanthrene. The results presented in Table 2 show the variety of environments in which the $\mathrm{PAH}$ can be found, revealing a special trend to performing the detection in aqueous media. Electrochemical and optical techniques have been the most employed transduction methods in this context. According to Fiel et al. ${ }^{11}$ the electrochemical transduction mode comprises a group of techniques capable to offer, besides the advantageous low LOD as shown in Table 2, other important characteristics for the development of an analytical method for PAHs detection, such as high accuracy, reliability, simplicity, and cost-effectiveness. On the other hand, Damborský et al. ${ }^{32}$ highlight in the optical biosensors their small sizes leading to the possibility of fabricating portable devices that enables real-time measurements. In contrast to the abovementioned advantages of the biosensors, Behera et al. ${ }^{10}$ also pointed out some controversial shortcomings referring to the use of immunoassays as analytical methods. According to them, some immunoassays are less sensitive than traditional gas chromatography coupled with mass spectrometry, for example, and can lead to some misinterpretation. Since some antibodies are capable to recognize certain functional groups in the chemical molecules, the similarity among different PAHs can cause the development of analytical signal due to the crossreactivity events, leading to the emergence of false positive results.

\section{Conclusion}

PAHs are important persistent pollutants present in the environment. Despite the variety of natural sources, the anthropogenic activity remains the greatest cause of PAHs emissions to the air, water and soil, posing severe risks to humans' health and to the life in the nature. In light of the challenging monitoring and regulation of PAHs in different ecosystems, various techniques have been employed to detect the presence and the quantity of these pollutants. However, the development of analytical methods for detecting PAHs faces a particular challenge: the plural sources in which these pollutants can be found in the environment, hindering not exclusively the identification of major sources of the organic pollutants but also the implementation of regulatory activities on environment monitoring. Moreover, traditional analytical methods currently available for this purpose are limited with respect to their cost, the time to perform the detection besides being considered very sophisticated. Thus, the introduction of the biosensors technology have been widely considered 
in the last years as an alternative to conventional techniques like chromatography and mass spectrometry. Biosensors combine the high selectivity of biological elements of recognition to the sensitivity of transduction substrates to recognize analytes for various applications. In the case of PAHs detection, DNA and antibodies have been the most employed probes and electrochemical and optical assays figured amongst the most used transduction techniques. The literature on this topic have shown very low LODs, selective response towards certain PAHs and the possibility of performing rapid or even real-time measurements in situ. Overall, these promising characteristics set the biosensing platforms as powerful tools to assist in the monitoring of ecosystems, although the state the art on this domain still need to be further exploited. ${ }^{33}$

\section{Funding details}

None.

\section{Acknowledgments}

The authors are thankful to Coordenação de Aperfeiçoamento de Pessoal de Nível Superior (CAPES) and Conselho Nacional de Desenvolvimento Científico e Tecnológico (CNPq).

\section{Conflict of interests}

Authors declare that there is no conflict of interest.

\section{References}

1. Kumari B, Singh DP. A review on multifaceted application of nanoparticles in the field of bioremediation of petroleum hydrocarbons. Eco Eng. 2016;97:98-105.

2. Pérez-Hernández I, Ochoa-Gaona S, Schroeder RHA, et al. Tolerance of four tropical tree species to heavy petroleum contamination. Water Air Soil Pollut. 2013;224:1637.

3. Bayat Z, Hassanshahian M, Cappello S. Immobilization of microbes for bioremediation of crude oil polluted environments: a review. Open Microbiol J. 2015;9:48-54.

4. Zaki MS, Authman MMN, Abbas HHH. Bioremediation of petroleum contaminants in aquatic environments. Life Sci J. 2015;12(5):109-121.

5. Agudelo-Castañeda DM, Teixeira EC, Schneider IL, et al. Exposure to polycyclic aromatic hydrocarbons in atmospheric PM 1.0 of urban environments: Carcinogenic and mutagenic respiratory health risk by age groups. Environ Pollut. 2017;224:158-170.

6. Ke CL, Gu YG, Liu Q, et al. Polycyclic aromatic hydrocarbons (PAHs) in wild marine organisms from South China Sea: Occurrence, sources, and human health implications. Mar Pollut Bull. 2017;117(1-2):507511.

7. Ghosal D, Ghosh S, Dutta TK, et al. Current State of Knowledge in Microbial Degradation of Polycyclic Aromatic Hydrocarbons (PAHs): A Review. Front Microbiol. 2016;7:1-27.

8. Abdel-Shafy HI, Mansour MSM. A review on polycyclic aromatic hydrocarbons: Source, environmental impact, effect on human health and remediation. Egypt J Pet. 2016;25:107-123.

9. Hahm E, Jeong D, Cha MG, et al. $\beta$-CD Dimer-immobilized Ag Assembly Embedded Silica Nanoparticles for Sensitive Detection of Polycyclic Aromatic Hydrocarbons. Sci Reports. 2016; 6(1):1-7.

10. Behera BK, Das A, Sarkar DJ, et al. Polycyclic Aromatic Hydrocarbons (PAHs) in inland aquatic ecosystems: Perils and remedies through biosensors and bioremediation. Environm Pollut. 2018;241:212-233.
11. Fiel WA, Borges PAF, Lins VFC, Faria RAD. Recent advances on the electrochemical transduction techniques for the biosensing of pharmaceuticals in aquatic environments. Int $J$ Biosen Bioelectron. 2019;5(4):119-123.

12. Faria RAD, Heneine LGD, Matencio T, et al. Recent trends in the electroanalytical detection of food fraud. Int $J$ Biosen Bioelectron. 2019;5(3):63-67.

13. Faria RAD, Lins VFC, Nappi GU, Matencio T, Heneine LGD. Development of an Impedimetric Immunosensor for Specific Detection of Snake Venom. BioNanoSci. 2018;8(4):988-996.

14. Wang C, Wu S, Zhou S, et al. Polycyclic aromatic hydrocarbons in soils from urban to rural areas in Nanjing: Concentration, source, spatial distribution, and potential human health risk. Sci Total Environm. 2015;527-528:375-383.

15. Chen Y, Lin T, Tang J, et al. Exchange of polycyclic aromatic hydrocarbons across the air-water interface in the Bohai and Yellow Seas. Atmosph Environm. 2016;141:153-160.

16. Mai L, Bao LJ, Liu LY, et al. Polycyclic aromatic hydrocarbons affiliated with microplastics in surface waters of Bohai and Huanghai Seas, China. Environm Pollut. 2018;241:834-840.

17. Louvado A, Gomes NCM, Simões MMQ, et al. Polycyclic aromatic hydrocarbons in deep sea sediments: Microbe-pollutant interactions in a remote environment. Sci Total Environm. 2015;526:312-328.

18. Zhang Y, Dong S, Wang H, et al. Biological impact of environmental polycyclic aromatic hydrocarbons (ePAHs) as endocrine disruptors. Environm Pollut. 2016;213:809-824.

19. Kim KH, Jahan SA, Kabir E, et al. A review of airbone polycyclic aromatic hydrocarbons (PAHs) and their human health effects. Environm Int. 2013;60:71-80.

20. Zelinkova Z, Wenzl T. The Occurrence of 16 EPA PAHs in Food - A Review. Polycycl Aromat Comp. 2015;35(2-4):248-284.

21. Samburova V, Zielinska B, Khlystov A. Do 16 polycyclic aromatic hydrocarbons represent pah air toxicity? Toxics. 2017;5(17):1-16.

22. Bolden AL, Rochester JR, Schultz K, et al. Polycyclic aromatic hydrocarbons and female reproductive health: A scoping review. Reprod Toxic. 2017;73:61-74.

23. International Agency for Research on Cancer. Monographs on the evaluation of carcinogenic risks to humans. Ingested nitrate and nitrite, and cyanobacterial peptide toxins. IARC Monographs Evaluation of Carcinogenic Risks to Humans. 2010;1-412.

24. Purcaro G, Barp L, Moret S. Determination of hydrocarbon contamination in foods. A review. Anal Methods. 2016; 8(29):5755-5772.

25. Ledesma E, Rendueles M, Díaz M. Contamination of meat products during smoking by polycyclic aromatic hydrocarbons: Processes and prevention. Food Control. 2016;60:64-87.

26. Fasano E, Yebra-Pimentel I, Martínez-Carballo E, et al. Profiling, distribution and levels of carcinogenic polycyclic aromatic hydrocarbons in traditional smoked plant and animal foods. Food Control. 2016;59:581-590.

27. Sun Y, Zhao X, Zhang D, et al. New naphthalene whole-cell bioreporter for measuring and assessing naphthalene in polycyclic aromatic hydrocarbons contaminated site. Chemosph. 2017;186:510-518.

28. Beloglazova NV, Lenain P, Rycke ED, et al. Capacitive sensor for detection of benzo(a)pyrene in water. Talanta. 2018;190:219-225.

29. Ni Y, Wang P, Song H, et al. Electrochemical detection of benzo(a) pyrene and related DNA damage using DNA/hemin/nafion-graphene biosensor. Anal Chim Acta. 2014;821:34-40. 
30. Fan Z, Li Z, Liu S, et al. Rapid fluorescence immunoassay of benzo[a] pyrene in mainstream cigarette smoke based on a dual-functional antibody-DNA conjugate. RSC Adv. 2018;8:29562-29569.

31. Meng XY, Li YS, Zhou Y, et al. Real-time immuno-PCR for ultrasensitive detection of pyrene and other homologous PAHs. Bios Bioelectron. 2015;70:42-47.
32. Fähnrich K, Pravda M, Guilbault G. Disposable amperometric immunosensor for the detection of polycyclic aromatic hydrocarbons (PAHs) using screen-printed electrodes. Bios Bioelectron. 2003;18(1):73-82.

33. Damborský P, Švitel J, Katrlík J. Optical biosensors. Essays Biochem. 2016;60(1):91-100. 